\title{
Erratum to: Defining and measuring literacy: Facing the reality
}

\author{
Manzoor Ahmed
}

Published online: 30 July 2011

(C) Springer Science+Business Media B.V. 2011

\section{Erratum to: Int Rev Educ \\ DOI 10.1007/s11159-011-9188-x}

This article is based on a substantially similar article originally published in the December 2010 edition of the Bangladesh Education Journal (Vol. 9 No. 2), entitled "Defining and Measuring Literacy - Implications for Policy and Programme". The present article was subjected to the International Review of Education's peer-review procedures prior to publication.

The online version of the original article can be found under doi:10.1007/s11159-011-9188-x.

M. Ahmed ( $\bowtie)$

Brac University Institute of Educational Development (BRACU-IED), Dhaka, Bangladesh e-mail: manzoor.ahmed@bracu.ac.bd 